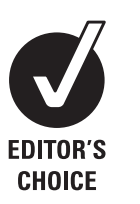

(

Bascom Palmer Eye Institute, University of Miami, Miami, Florida, USA

\section{Correspondence to} Dr C L Karp, Bascom Palmer Eye Institute, 900 NW 17 Street, Miami, FL 33136, USA; ckarp@med.miami.edu

Accepted 29 March 2009 Published Online First 2 June 2009

\title{
Topical interferon alpha $2 b$ eye-drops for treatment of ocular surface squamous neoplasia: a dose comparison study
}

\author{
A Galor, C L Karp, S Chhabra, S Barnes, E C Alfonso
}

\begin{abstract}
Background/aims To compare the effectiveness and side-effect profile of two doses of interferon alpha2b (IFNa2b) eye-drops (1 million international units (IU)/ml versus 3 million $\mathrm{IU} / \mathrm{ml}$ ) in the treatment of ocular surface squamous neoplasia (OSSN).

Methods Retrospective case series.

Results Thirty-five eyes were identified over an 11-year period (1996-2007). Twenty-one eyes (19 patients) with conjunctival intraepithelial neoplasia (CIN) were treated with 1 million IU/ml of topical IFN- $\alpha 2 b$; 12 eyes (nine patients) with CIN were treated with 3 million IU/ $\mathrm{ml}$. Two patients with squamous cell carcinoma (SCC) were treated with topical interferon, one with 1 million $\mathrm{IU} / \mathrm{ml}$ and one with 3 million $\mathrm{IU} / \mathrm{ml}$. Baseline demographic information was not statistically different between the two groups. In patients with CIN, topical therapy eliminated disease in $81 \%$ of eyes in the 1 million $\mathrm{IU} / \mathrm{ml}$ group versus $92 \%$, in the 3 million $\mathrm{IU} / \mathrm{ml}$ group, $p=0.41$. The median time to OSSN resolution was 2.8 months in the 1 million $\mathrm{IU} / \mathrm{ml}$ group and 1.9 months in the 3 million $\mathrm{IU} / \mathrm{ml}$ group, $p=0.55$. Neither eye with SCC responded to interferon therapy. Topical therapy was well tolerated. After a median follow-up of 24 months, three recurrences were seen in eyes successfully treated with topical therapy.
\end{abstract}

Conclusion In our study, there were no significant differences between the 1 million $\mathrm{IU} / \mathrm{ml}$ group and the 3 million $\mathrm{IU} / \mathrm{ml}$ group for the treatment of CIN.

The traditional treatment for ocular surface squamous neoplasia (OSSN) has been surgical excision, often with adjunctive cryotherapy. However, given the risk of recurrent disease and the potential for limbal stem cell deficiency with repeated excisions, medical therapy has become important in the treatment of this condition. ${ }^{1}$ Mitomycin C (MMC), 5-fluorouracil and interferon therapy have all been reported to successfully treat OSSN. ${ }^{1-12}$ Along with potentially avoiding stem cell deficiency, medical therapy has the advantage of treating microscopic disease that may be present throughout the entire ocular surface.

Interferons are a group of naturally occurring proteins that help the immune system handle endogenous and exogenous threats to the body. Interferons have been used in the treatment of many disorders, including hepatitis, ${ }^{13}$ cervical intraepithelial neoplasia ${ }^{14}$ and cutaneous squamous cell carcinoma. ${ }^{15}$ Topical drops and subconjunctival injections of interferon- $\alpha 2 b$ (INF- $\alpha 2 b$ ) have been used as off-label therapy to treat OSSN. ${ }^{2} 81617$
No studies have evaluated the ideal dose of topical INF- $\alpha 2 b$ eye-drops. Two standard doses are prepared by the compounding pharmacy at the Bascom Palmer Eye Institute (BPEI): 1 million and 3 million international unit/ml (IU). The 1 million $\mathrm{IU} / \mathrm{ml}$ dose was the empirical dose used in our initial study. ${ }^{16}$ The mean time to tumour resolution was about 12 weeks; this time was similar to other studies using this dose. ${ }^{2} 1718$ The 3 million $\mathrm{IU} / \mathrm{ml}$ dose was later compounded in an attempt to shorten the duration of treatment. The 3 million $\mathrm{IU} / \mathrm{ml}$ dose was chosen, as it is the dose used with subconjunctival injections. The cost of the 3 million $\mathrm{IU} / \mathrm{ml}$ dose at our institution is significantly higher than the 1 million $\mathrm{IU} / \mathrm{ml}$ dose. While a prospective study would be preferable to evaluate the efficacy and side-effect profile of the two doses, such a study is impractical given the small numbers of patients treated with topical therapy alone. We therefore conducted a retrospective analysis to compare the effectiveness and side-effect profile of the 1 million and 3 million $\mathrm{IU} / \mathrm{ml}$ doses in order to make recommendations on the optimal dose of the medication in OSSN.

\section{MATERIALS AND METHODS \\ Study population}

The University of Miami Institutional Review Board reviewed and approved this study, which was conducted in accordance with the principles of the Declaration of Helsinki. Patients who were treated with topical IFN- $\alpha 2 b$ eye-drops for OSSN (conjunctival intraepithelial neoplasia (CIN) and squamous cell carcinoma (SCC)) at the BPEI were included in the study. Since all topical IFN- $\alpha 2 b$ eye-drops are made by the compounding pharmacy at BPEI, patients were identified by searching for topical IFN- $\alpha 2 b$ eye-drop prescriptions dispensed between the years of 1996 and 2007 . We chose to include all patients treated with interferon eye-drops, both biopsy-proven and clinically diagnosed. Patients with primary or recurrent OSSN were included in the analysis. Patients were excluded from the analysis if they were treated with concomitant MMC, if they received subconjunctival injections of IFN- $\alpha 2 b$, or if the eye-drops were given as an adjuvant to complete surgical excision. Both eyes of a single patient were included in the analysis if applicable. At our institution, all patients are treated with interferon drops four times daily. Topical therapy is typically continued for approximately 1 month after lesion resolution. 


\section{Data collection}

All data were obtained via a retrospective chart review and entered into a standardised computerised database for subsequent analysis. The data collected included demographic characteristics, pretreatment objective findings, treatment information and post-treatment course. The main outcome measure was time to clinical resolution of tumour.

\section{Statistical analysis}

All statistical analyses were performed using the SPSS (SPSS, Chicago) statistical package. Frequencies of demographic and clinical variables were calculated for each treatment group. Categorical variables were compared using the $\chi^{2}$ test. Continuous variables were analysed by comparing median values using the Mann-Whitney test. All $p$ values are two-sided and nominal. Time-to-event curves were calculated using the Kaplan-Meier method. Hazard ratios were calculated with Cox proportional hazards modelling.

\section{RESULTS}

\section{Study population at presentation}

Thirty-three eyes with CIN were treated with topical interferon. Their demographics are summarised in table 1.

Twenty-one eyes (19 patients) were treated with 1 million IU/ $\mathrm{ml}$ of topical IFN- $\alpha 2 \mathrm{~b} ; 12$ eyes (nine patients) were treated with 3 million IU $/ \mathrm{ml}$ of topical IFN- $\alpha 2 b$. Both groups used the interferon eye-drops four times daily until the lesion resolved, and the drops were then continued for approximately one more month. There were no statistically significant differences between the groups. Four eyes with CIN had been previously treated with interferon eye-drops. Two patients had tumours that were treated with interferon alone; both had a complete response to treatment. Two patients underwent surgical excision of their tumour; topical interferon was prescribed afterwards because the surgical margins were positive for tumour. These four eyes had a recurrence of tumour, and the patients were then treated with topical interferon and included in our study. Four patients with bilateral disease were treated with topical interferon, and each eye was analysed separately. One patient received two courses of interferon drops in the same eye. This patient had two distinct tumours at different times in the same eye, and each course was analysed separately.

Two patients with SSC were treated with topical interferon. Both were cases in which extensive surgery would be needed for cure, and the patients wanted a trial of medical therapy. One patient was 92 years old and wanted to try interferon drops as

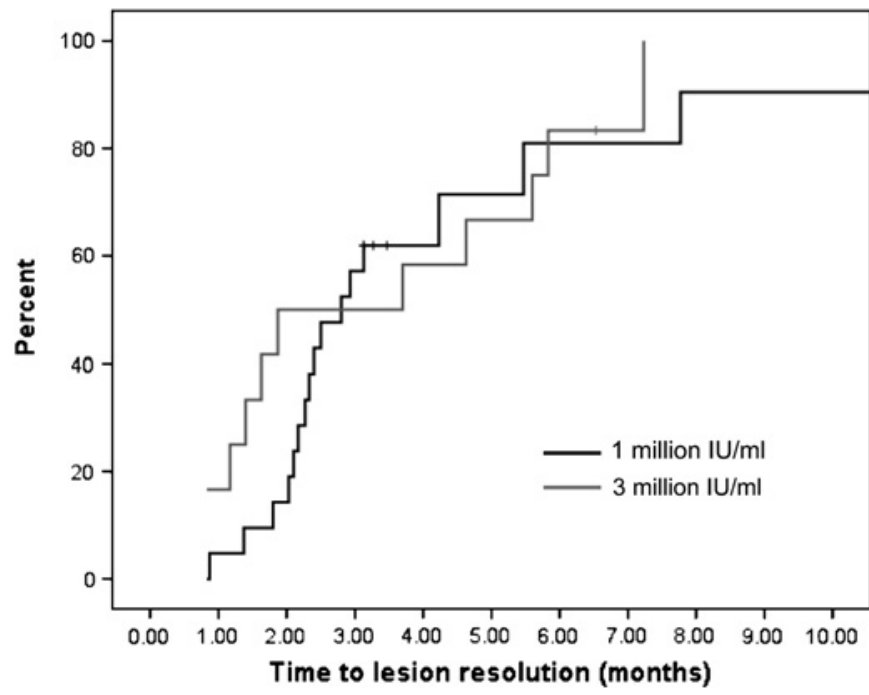

Figure 1 Survival curve of time to ocular surface squamous neoplasia resolution in patients treated with 1 million $\mathrm{IU} / \mathrm{ml}$ of topical interferon versus 3 million $\mathrm{IU} / \mathrm{ml}$ eye-drops ( $\mathrm{p}$ value $=0.54$ ).

an alternative to surgical intervention; he was treated with the 3 million IU/ml dose. Another patient had diffuse SSC which was not amendable to surgical removal; he was started on 1 million $\mathrm{IU} / \mathrm{ml}$ of interferon in hopes of chemoreducing the tumour to avoid enucleation.

\section{Treatment information}

Topical therapy alone was successful at eliminating CIN in a similar percentage of patients in both groups $(81 \%$ of eyes in the $1 \mathrm{million} \mathrm{IU} / \mathrm{ml}$ group vs $92 \%$ in the 3 million $\mathrm{IU} / \mathrm{ml}$ group, $\mathrm{p}=0.41$ ). While the time to CIN resolution was not significantly different between the groups (median 2.8 months in 1 million $\mathrm{IU} / \mathrm{ml}$ group and 1.9 months in 3 million $\mathrm{IU} / \mathrm{ml}$ group), there was a trend towards faster elimination in the 3 million $\mathrm{IU} / \mathrm{ml}$ group (table 2, Figure 1).

Topical interferon therapy was well tolerated, although there was a trend towards higher side effects in the 3 million $\mathrm{IU} / \mathrm{ml}$ group. The most common side effects were ocular discomfort and photophobia. The median treatment time was longer than the time to CIN resolution (median of 3.6 months in the 1 million IU/ml group and 4.3 months in the 3 million $\mathrm{IU} / \mathrm{ml}$ group, $\mathrm{p}=0.55)$, as treatment is normally continued for about a month after lesion resolution. In the seven eyes with a clinical

Table 1 Demographic information and lesion characteristics in patients with conjunctival intraepithelial neoplasia (CIN)

\begin{tabular}{lccc}
\hline & $\mathbf{1}$ million IU/ml & 3 million IU/ml & p Value \\
\hline No of eyes (patients) & $21(19)$ & $12(9)$ & \\
Median age (years (range)) & $60(23$ to 82$)$ & $72(36$ to 82$)$ & 0.44 \\
Gender (percentage male) (n/N) & $26 \%(5 / 19)$ & $56 \%(5 / 9)$ & 0.13 \\
Race & & & \\
$\quad$ Percentage white (n/N) & $42 \%(8 / 19)$ & $67 \%(6 / 9)$ & 0.43 \\
$\quad$ Percentage Hispanic (n/N) & $53 \%(10 / 19)$ & $33 \%(3 / 9)$ & 0.95 \\
Involved eye (percentage right eye) (n/N) & $43 \%(9 / 21)$ & $42 \%(5 / 12)$ & 1.00 \\
Recurrent ocular surface squamous & $33 \%(7 / 21)$ & $33 \%(4 / 12)$ & 0.55 \\
neoplasia (n/N) & $10 \%(2 / 21)$ & $17 \%(2 / 12)$ & 0.99 \\
Previous interferon use (topical or & & & \\
injections) & $19(2$ to 88$)$ & $23.8(2$ to 120$)$ & 0.20 \\
Median area of CIN (mm² (range)) & $86 \%(18 / 21)$ & $67 \%(8 / 12)$ & \\
Biopsy proven CIN* & &
\end{tabular}

*Biopsy of either previous or current lesion. 
Table 2 Treatment information in patients treated with topical interferon for conjunctival intraepithelial neoplasia (CIN)

\begin{tabular}{|c|c|c|c|}
\hline & $1 \mathrm{million} \mathrm{IU} / \mathrm{ml}$ & 3 million IU/ml & p Value \\
\hline Topical therapy successful at eliminating CIN & $81 \%(17 / 21)$ & $92 \%(11 / 12)$ & 0.41 \\
\hline $\begin{array}{l}\text { Median time (months) to CIN resolution (95\% } \\
\text { confidence interval) }(n)^{*}\end{array}$ & $2.8(2.0$ to 3.5$)(17)$ & $1.9(0.0$ to 5.4$)(11)$ & 0.55 \\
\hline Median time (months) on therapy* (range) (n) & $3.6(0.9$ to 14.7$)(17)$ & $4.3(1.3$ to 10.2$)(11)$ & 0.55 \\
\hline Side effects of therapy & $10 \%(2 / 21)$ & $17 \%(2 / 12)$ & \\
\hline Ocular discomfort & 2 & 1 & 0.55 \\
\hline Photophobia & 0 & 1 & \\
\hline Median time (months) of follow-up (range) (n) & $19.7(3.1$ to 116$)(21)$ & $47.4(1.4$ to 86$)(12)$ & 0.53 \\
\hline
\end{tabular}

*In patients with successful resolution on topical therapy

diagnosis of CIN, all lesions completely resolved with interferon therapy.

The CIN in five eyes did not respond completely to interferon eye-drop therapy; four of these five eyes were recurrent CIN. Patients with a prior history of CIN responded less well to therapy than those with no such history (HR $0.41,95 \% \mathrm{CI}(0.16$ to 1.03), $\mathrm{p}=0.06$ ). Failure of treatment required adjuvant therapy; complete surgical excision was utilised in two patients, and MMC eye-drops were used in three eyes (table 3). After the additional therapy, all of eyes achieved clinical resolution.

After a median follow-up of 24 months, three of the eyes successfully treated with topical IFN- $\alpha 2 b$ experienced a recurrence of the CIN lesion 20,21 and 28 months after initial tumour resolution. Both patients with SCC failed topical therapy. The 92-year-old patient underwent surgical excision and was continued on topical interferon after surgery due to positive residual margins; the patient with diffuse SCC underwent enucleation. Neither patient has had a recurrence of disease.

\section{DISCUSSION}

Interferon $\alpha$ is a potent protein with antitumour activity against a number of cancers including malignant melanoma, ${ }^{19}$ hepatocellular carcinoma ${ }^{20}$ and cervical neoplasia. ${ }^{21} 22$ We consider using IFN $\alpha 2 b$ therapy in the treatment of OSSN when lesions are annular ( $>4$ clock hours of limbal involvement) or in lesions that recur after primary surgical management. Two forms of IFN $\alpha 2 b$ therapy are currently used: subconjunctival/perilesional injections and topical drop therapy. The use of topical therapy is advantageous with regard to its side-effect profile (ie, no fever, chills, malaise). However, it requires a longer length of treatment, is more costly and does not have the benefit of ensuring patient compliance. Subconjunctival injections are normally given weekly at a cost of approximately $\$ 65 /$ injection, and patients receive an average of six injections. ${ }^{8} \mathrm{MMC}$ eye-drops $(0.02 \%$ to $0.04 \%)$ are the other main medical therapy used in OSSN; they are dosed four times daily at a cost of approximately $\$ 180 /$ cycle, with clinical resolution occurring in most cases by two cycles. ${ }^{3}$ However, local side effects including pain and redness are more severe with $\mathrm{MMC}$ compared with interferon.
Several series have evaluated the use of topical interferon for the treatment of CIN. Schechter et al evaluated the use of IFN $\alpha 2 b$ (most patients treated with 1 million $\mathrm{IU} / \mathrm{ml}$, four times daily, a minority with 3 million $\mathrm{IU} / \mathrm{ml}$, four times daily) as a single therapeutic agent in 28 eyes of 26 patients with CIN and found that $96 \%$ of eyes achieved complete remission with therapy. ${ }^{17}$ One patient had disease recurrence after stopping therapy. Boehm and Huang evaluated IFNa2b (1 million IU/ml, four times daily) in seven patients with presumed recurrent CIN and found that six of the seven patients responded successfully to treatment. ${ }^{2}$ Two patients experienced a recurrence after stopping therapy.

While the time to lesion resolution (median 2.4 months) and required length of treatment (median 3.8 months) was similar between our study and the published literature, the percentage of patients with complete lesion resolution on topical therapy alone was slightly lower in our study (85\%). It is important to note that some patients from Schechter's cohort were included in our study. The lower percentage of lesions responding to topical interferon may be explained by the referral nature of our practice. We see many patients with extensive, recurrent lesions as patients often present with the goal of avoiding extensive excision/surgery.

Side effects were mild in both our cohort and the published literature, suggesting that topical therapy is well tolerated. Studies utilising topical interferon either reported no side effects of treatment, ${ }^{2}$ a mild punctuate epithelial keratitis ${ }^{4}$ or mild conjunctival hyperaemia and follicular conjunctivitis. ${ }^{16} 17$ When side effects developed, they completely resolved within 1 month after stopping therapy. One publication did report on the development of epithelial microcystic oedema which persisted after discontinuation of therapy. ${ }^{23}$

No study has specifically evaluated the optimal dosage of IFNa2b therapy. The two doses compounded by the BPEI pharmacy are 1 and 3 million $\mathrm{IU} / \mathrm{ml}$. The cost of the 3 million $\mathrm{IU} / \mathrm{ml}$ dose is at the time of this writing substantially higher than the 1 million $\mathrm{IU} / \mathrm{ml}$ dose ( $\$ 260$ for a $5 \mathrm{ml}$ bottle compared with \$120). No data exist on whether the higher dose is justified with respect to time to lesion resolution, disease recurrence and side-effect profile. Although our study is small and therefore has limited power, our findings suggest that no large clinical

Table 3 Therapy failures and recurrence of disease in patients treated with topical interferon for conjunctival intraepithelial neoplasm (CIN)

\begin{tabular}{llcc}
\hline & $\mathbf{1}$ million IU/ml & $\mathbf{3 ~ m i l l i o n ~ I U / m I}$ & p Value \\
\hline $\begin{array}{l}\text { Topical therapy alone unsuccessful at eliminating CIN } \\
\text { Salvage therapy after failure of topical interferon- } \alpha 2 \mathrm{~b}\end{array}$ & $19 \%(4 / 21)$ & $9 \%(1 / 12)$ & 0.41 \\
$\quad$ & 2 & & \\
$\quad$ Surgical removal of lesion & 2 & 1 & \\
$\quad$ Mitomycin C & $100 \%(4 / 4)$ & $100 \%(1 / 1)$ & 1.00 \\
Resolution of CIN after salvage therapy & $12 \%(2 / 17)$ & $9 \%(1 / 11)$ & 0.82 \\
CIN recurrence in eyes where topical therapy successful & &
\end{tabular}


differences exist in tumour response between the two IFN- $\alpha 2 b$ doses. There may be a trend for faster resolution and increased side effects in the 3 million $\mathrm{IU} / \mathrm{ml}$ group. In light of these overall considerations, we recommend using the 1 million $\mathrm{IU} / \mathrm{ml}$ dose in the treatment of CIN.

As with all retrospective studies, our conclusions must be interpreted cautiously due to the limitations of the study. Our conclusions are based on the assumption that the baseline characteristics between the two groups were similar. The groups were not identical with respect to many factors. This may have skewed the results if the CIN lesions in the 3 million IU/ml group were more aggressive than in the 1 million $\mathrm{IU} / \mathrm{ml}$ group. Patients with both primary and recurrent disease were included in the analysis. Although an equal proportion of patients in each group had recurrent disease, this may have also skewed our results. In addition, more patients with bilateral disease were treated with 3 million $\mathrm{IU} / \mathrm{ml}$ of interferon. This introduces a correlation bias as eyes of the same patient are expected to respond similarly to treatment. Finally, we included both biopsyproven and clinically diagnosed lesions in our analysis; however, we feel justified in this decision due to the high clinical accuracy of diagnosing CIN. Due to the small number of eyes with CIN treated with topical interferon therapy alone, and the retrospective nature of the study, these limitations are difficult to eliminate. A larger, multicentred study with more patients and longer follow-up will be necessary to confirm our findings.

Funding Unrestricted funds from Research to Prevent Blindness.

Competing interests None.

Ethics approval Ethics approval was provided by University of Miami Institutional Review Board.

Provenance and peer review Not commissioned; externally peer reviewed.

\section{REFERENCES}

1. Poothullil AM, Colby KA. Topical medical therapies for ocular surface tumors. Semin Ophthalmol 2006;21:161-9.

2. Boehm MD, Huang AJ. Treatment of recurrent corneal and conjunctival intraepithelial neoplasia with topical interferon alfa 2b. Ophthalmology 2004;111:1755-61.

3. Frucht-Pery J, Sugar J, Baum J, et al. Mitomycin C treatment for conjunctivalcorneal intraepithelial neoplasia: a multicenter experience. Ophthalmology 1997; 104:2085-93.
4. Kobayashi A, Yoshita T, Uchiyama K, et al. Successful management of conjunctival intraepithelial neoplasia by interferon alpha-2b. Jpn J Ophthalmol 2002; 46:215-17.

5. Majmudar PA, Epstein RJ. Antimetabolites in ocular surface neoplasia. Curr Opin Ophthalmol 1998;9:35-9.

6. Prabhasawat $\mathbf{P}$, Tarinvorakup $P$, Tesavibul N, et al. Topical $0.002 \%$ mitomycin $C$ for the treatment of conjunctival-corneal intraepithelial neoplasia and squamous cell carcinoma. Cornea 2005;24:443-8.

7. Rozenman $\mathbf{Y}$, Frucht-Pery J. Treatment of conjunctival intraepithelial neoplasia with topical drops of mitomycin C. Cornea 2000;19:1-6.

8. Vann RR, Karp CL. Perilesional and topical interferon alfa-2b for conjunctival and corneal neoplasia. Ophthalmology 1999;106:91-7.

9. Yeatts RP, Engelbrecht NE, Curry CD, et al. 5-Fluorouracil for the treatment of intraepithelial neoplasia of the conjunctiva and cornea. Ophthalmology 2000;107:2190-5.

10. Yeatts RP, Ford JG, Stanton CA, et al. Topical 5-fluorouracil in treating epithelial neoplasia of the conjunctiva and cornea. Ophthalmology 1995;102:1338-44.

11. Wilson MW, Hungerford JL, George SM, et al. Topical mitomycin C for the treatment of conjunctival and corneal epithelial dysplasia and neoplasia. Am J Ophthalmol 1997;124:303-11.

12. Heigle TJ, Stulting RD, Palay DA. Treatment of recurrent conjunctival epithelial neoplasia with topical mitomycin C. Am J Ophthalmol 1997;124:397-9.

13. Chevaliez S, Pawlotsky JM. Interferon-based therapy of hepatitis C. Adv Drug Deliv Rev 2007;59:1222-41.

14. Chakalova G, Ganchev G. Local administration of interferon-alpha in cases of cervical intraepithelial neoplasia associated with human papillomavirus infection. $J$ Buon 2004;9:399-402.

15. Edwards L, Berman B, Rapini RP, et al. Treatment of cutaneous squamous cell carcinomas by intralesional interferon alfa-2b therapy. Arch Dermatol 1992; 128:1486-9.

16. Karp CL, Moore JK, Rosa RH Jr. Treatment of conjunctival and corneal intraepithelial neoplasia with topical interferon alpha-2b. Ophthalmology 2001;108:1093-8.

17. Schechter BA, Koreishi AF, Karp CL, et al. Long-term follow-up of conjunctival and corneal intraepithelial neoplasia treated with topical interferon alfa-2b. Ophthalmology 2008;115:1291-6.

18. Schechter BA, Schrier A, Nagler RS, et al. Regression of presumed primary conjunctival and corneal intraepithelial neoplasia with topical interferon alpha-2b. Cornea 2002;21:6-11.

19. Hauschild A, Gogas $H$, Tarhini A, et al. Practical guidelines for the management of interferon-alpha-2b side effects in patients receiving adjuvant treatment for melanoma: expert opinion. Cancer 2008;112:982-94.

20. Vitale FV, Romeo P, Vasta F, et al. Hepatic intra-arterial interferon alpha 2b-based immunotherapy combined with 5-fluorouracil (5-FU)-based systemic chemotherapy for patients with hepatocellular carcinoma (HCC) not responsive and/or not eligible for conventional treatments: a pilot study. Anticancer Res 2007; 27:4077-81

21. Santhanam S, Decatris M, O'Byrne K. Potential of interferon-alpha in solid tumours: part 2. BioDrugs 2002;16:349-72.

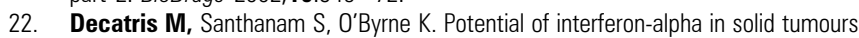
part 1. BioDrugs 2002;16:261-81.

23. Aldave AJ, Nguyen A. Ocular surface toxicity associated with topical interferon alpha-2b. Br J Ophthalmol 2007;91:1087-8. 